\title{
Chronic Hepatitis E Infection in a Persistently Immunosuppressed Patient Unable to Be Eliminated after Ribavirin Therapy
}

\author{
Masato Miyoshi ${ }^{1,2}$, Sei Kakinuma ${ }^{2,3}$, Yoko Tanabe ${ }^{1}$, Koji Ishii ${ }^{4}$, Tian-Cheng $\mathrm{Li}^{4}$, \\ Takaji Wakita $^{4}$, Yukio Tsuura ${ }^{5}$, Hideki Watanabe ${ }^{1}$, Yasuhiro Asahina ${ }^{2,3}$, \\ Mamoru Watanabe ${ }^{2}$ and Takaaki Ikeda ${ }^{1}$
}

\begin{abstract}
Recent case reports have shown that hepatitis E virus (HEV) infection can cause chronic hepatitis in immunosuppressed or immunocompromised patients. A 37-year-old woman suffered from prolonged elevation of aminotransferases after chemotherapy for Burkitt's lymphoma and was diagnosed with chronic hepatitis $\mathrm{E}$ due to a transfusion during chemotherapy. After an 8-month administration of ribavirin, complete HEV clearance was not achieved, likely due to prolonged hypogammaglobulinemia. This case indicates that HEV infection should be ruled out during liver dysfunction in immunosuppressed or immunocompromised patients and suggests that an alternative therapeutic strategy for such patients will be needed.
\end{abstract}

Key words: hepatitis E virus, chronic hepatitis, blood transfusion, immunocompromised host, rituximab, hypogammaglobulinemia

(Intern Med 55: 2811-2817, 2016)

(DOI: 10.2169/internalmedicine.55.7025)

\section{Introduction}

Hepatitis E virus (HEV) was first identified as a cause of nonA-nonB acute hepatitis in developing countries in the 1980s (1). HEV belongs to the genus Orthohepevirus in the Hepeviridae family. HEV is divided into four genotypes. Genotypes 1 and 2 are prevalent in several developing countries, where they are transmitted through the oral-fecal route and infect only humans. Genotypes 3 and 4 are responsible for sporadic acute hepatitis in developed countries. These viruses are zoonotic and can infect not only humans, but also pigs, deer and other wild mammals (2).

HEV typically causes acute hepatitis and is a self-limiting infection. However, the first case report from France in 2008 showed that HEV can cause chronic hepatitis, referred to as chronic hepatitis $\mathrm{E}$ (CH-E), in patients following organ transplantation (3). CH-E has also developed in patients with hematologic diseases and immunocompromised patients such as those receiving chemotherapy or immunosuppressive treatment or individuals infected with human immunodeficiency virus (4-6). Furthermore, CH-E causes relatively rapid fibrosis (7). Previous case reports from Europe have shown that ribavirin administration is effective for CH-E that develops in recipients of organ transplantation (8). We herein report the first case of CH-E in Japan. The patient was treated with intensive chemotherapy for Burkitt's lymphoma and was infected with HEV by a blood transfusion during chemotherapy. The patient started oral ribavirin therapy, however, was unable to eliminate the chronic HEV infection even after 8-month treatment of ribavirin, presumably due to prolonged hypogammaglobulinemia after the end of chemotherapy.

\footnotetext{
${ }^{1}$ Department of Gastroenterology and Hepatology, Yokosuka Kyosai Hospital, Japan, ${ }^{2}$ Department of Gastroenterology and Hepatology, Tokyo Medical and Dental University, Japan, ${ }^{3}$ Department for Liver Disease Control, Tokyo Medical and Dental University, Japan, ${ }^{4}$ Department of Virology II, National Institute of Infectious Diseases, Japan and ${ }^{5}$ Department of Pathology, Yokosuka Kyosai Hospital, Japan Received for publication December 22, 2015; Accepted for publication January 28, 2016 Correspondence to Dr. Masato Miyoshi, mmiyoshi.gast@tmd.ac.jp
} 


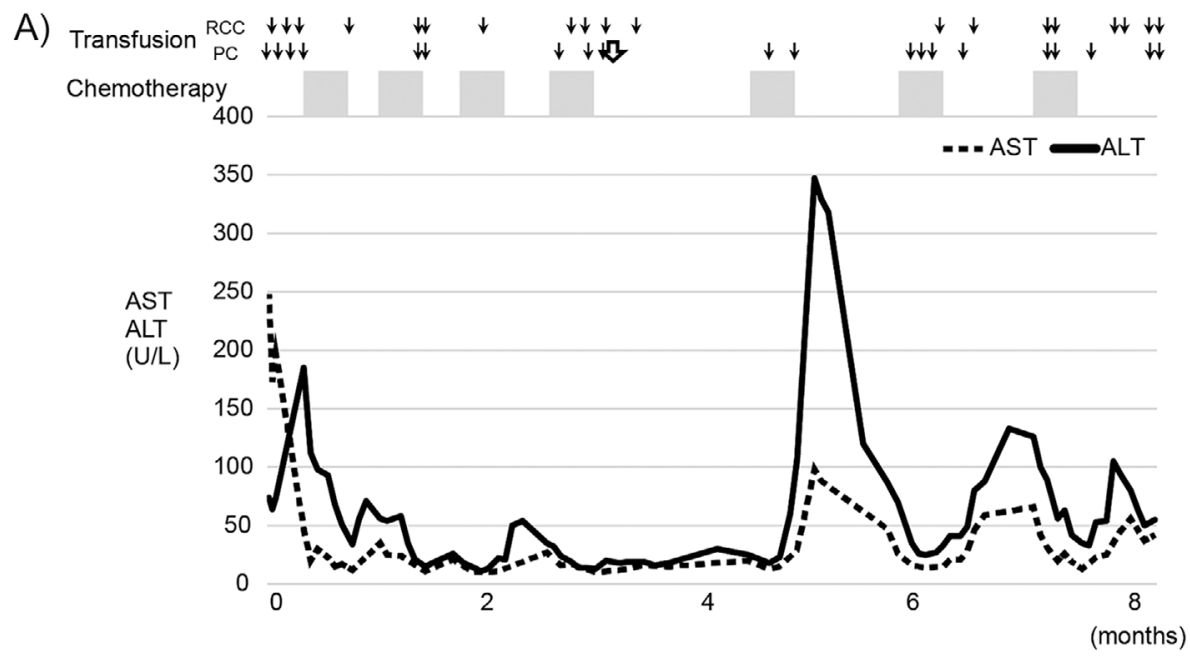

B)

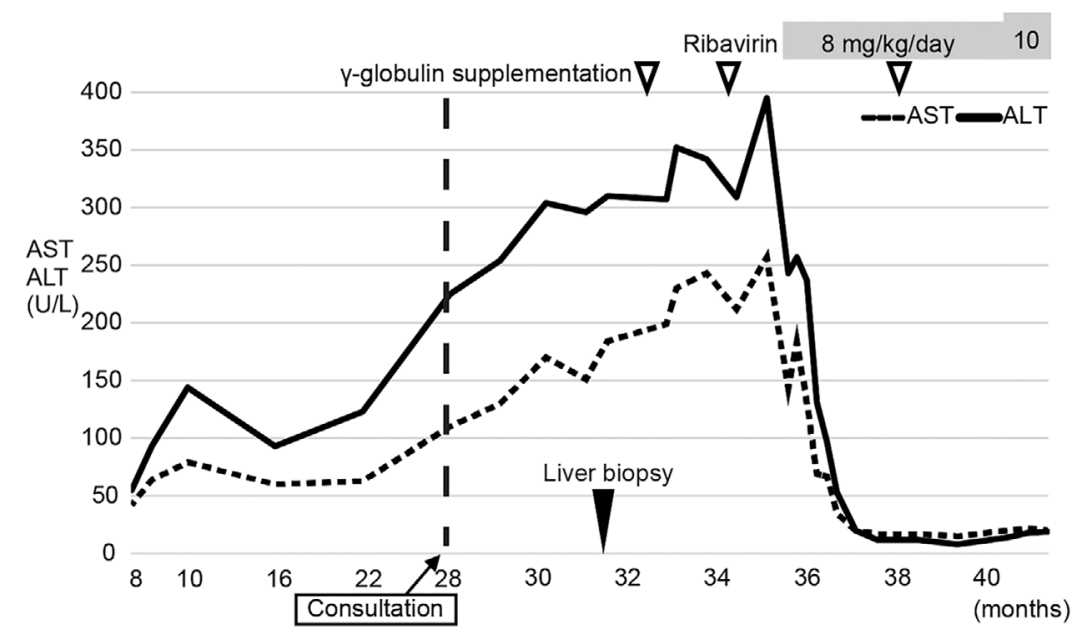

Figure 1. The clinical course of this patient. (A) The clinical course during chemotherapy after the diagnosis of lymphoma. The $\mathrm{x}$ axis represents time from the diagnosis of lymphoma. The normal line and dotted line show ALT and AST, respectively. The arrows, white arrow, and closed square represent transfusion, hepatitis $\mathrm{E}$ virus (HEV)-contaminated transfusion, and chemotherapy, respectively. (B) The clinical course after the end of chemotherapy. Black and white arrowheads represent the liver biopsy and supplementation of gamma globulin, respectively. "Consultation" represents the time point when the patient visited the Department of Gastroenterology and Hepatology.

\section{Case Report}

A 37-year-old Japanese woman visited the Department of Gastroenterology and Hepatology, Yokosuka Kyosai Hospital for a workup of prolonged elevation of serum aminotransferases. Her past history included Burkitt's lymphoma that had developed approximately 2.5 years previously. She had no other significant medical history aside from lymphoma. Before her initial treatment for Burkitt's lymphoma, her white blood cell count was $88,300 / \mu$ L. Serum biochemical data results at this time were: lactate dehydrogenase (LDH) 9,745 U/L, aspartate aminotransferase (AST) $248 \mathrm{U} / \mathrm{L}$, alanine aminotransferase (ALT) $74 \mathrm{U} / \mathrm{L}, \gamma$-glutamyl transpeptidase ( $\gamma$ GTP) $546 \mathrm{U} / \mathrm{L}$, and alkaline phosphatase (ALP) $541 \mathrm{U} / \mathrm{L}$. She subsequently developed multi-organ failure (MOF) due to tumor lysis syndrome and received intensive care against MOF, followed by anti-cancer therapy for lym- phoma. She received the curative anti-cancer chemotherapy regimen R-Hyper CVAD, which included rituximab, cyclophosphamide, vincristine, doxorubicin and cytarabine. She received frequent blood transfusions due to serious bone marrow suppression caused by chemotherapy. A total of 36 units of red blood cells and 240 units of platelet concentrates were administered.

The laboratory data revealed abnormal elevation of serum transaminases after her recovery from bone marrow suppression during the 5th course of chemotherapy. A peak elevation of aminotransferases (AST 98 U/L, ALT 347 U/L) was observed 20 days after the initiation of her 5th chemotherapy course (Fig. 1A). Her transaminase levels then decreased for several days. Similarly, transient liver dysfunction was observed during the 6th and 7th chemotherapy courses (Fig. 1A). After the 7th course, she developed hemorrhagic cystitis due to continuous adenovirus infection. Thus, her bone marrow suppression was considered to be 
Table. The Test Results of Blood Examinations.

\begin{tabular}{|c|c|c|c|c|c|c|c|c|}
\hline WBC & 3,300 & $/ \mu \mathrm{L}$ & $\mathrm{LDH}$ & 159 & $\mathrm{U} / \mathrm{L}$ & $\mathrm{IgG}$ & 238.8 & $\mathrm{mg} / \mathrm{dL}$ \\
\hline Neutro & 45.5 & $\%$ & AST & 70 & $\mathrm{U} / \mathrm{L}$ & $\operatorname{IgA}$ & 3 & $\mathrm{mg} / \mathrm{dL}$ \\
\hline Eo & 0 & $\%$ & ALT & 111 & $\mathrm{U} / \mathrm{L}$ & IgM & 12.7 & $\mathrm{mg} / \mathrm{dL}$ \\
\hline $\mathrm{Ba}$ & 0.5 & $\%$ & ALP & 196 & $\mathrm{U} / \mathrm{L}$ & ANA & neg & \\
\hline Mo & 11 & $\%$ & $\gamma$-GTP & 229 & $\mathrm{U} / \mathrm{L}$ & AMA & neg & \\
\hline Ly & 43 & $\%$ & CK & 18 & $\mathrm{U} / \mathrm{L}$ & ASMA & neg & \\
\hline $\mathrm{RBC}$ & 3.89 & $\times 10^{6}$ & T-bil & 0.6 & $\mathrm{mg} / \mathrm{dL}$ & & & \\
\hline $\mathrm{Hb}$ & 12.7 & $\mathrm{~g} / \mathrm{dL}$ & D-bil & 0.1 & $\mathrm{mg} / \mathrm{dL}$ & HBs Ag & neg & \\
\hline \multirow[t]{2}{*}{ Plt } & 16.6 & $\times 10^{4}$ & BUN & 8 & $\mathrm{mg} / \mathrm{dL}$ & $\mathrm{HBc} \mathrm{Ab}$ & neg & \\
\hline & & & Cre & 0.45 & $\mathrm{mg} / \mathrm{dL}$ & $\mathrm{HCV} \mathrm{Ab}$ & neg & \\
\hline РТ\% & $>100$ & $\%$ & CRP & 0.32 & $\mathrm{mg} / \mathrm{dL}$ & HIV Ab & neg & \\
\hline PT-INR & 0.98 & & $\mathrm{Na}$ & 141 & $\mathrm{mEq} / \mathrm{L}$ & & & \\
\hline \multirow[t]{6}{*}{ APTT } & 30.1 & $\sec$ & $\mathrm{K}$ & 4.8 & $\mathrm{mEq} / \mathrm{L}$ & & & \\
\hline & & & $\mathrm{Cl}$ & 103 & $\mathrm{mEq} / \mathrm{L}$ & & & \\
\hline & & & Glu & 109 & $\mathrm{mg} / \mathrm{dL}$ & & & \\
\hline & & & HDL & 64 & $\mathrm{mg} / \mathrm{dL}$ & & & \\
\hline & & & LDL & 61 & $\mathrm{mg} / \mathrm{dL}$ & & & \\
\hline & & & TG & 194 & $\mathrm{mg} / \mathrm{dL}$ & & & \\
\hline
\end{tabular}

\begin{tabular}{ll} 
(B) & \\
\hline HA-IgM & neg \\
HA-IgG & neg \\
HEV-IgA & neg \\
EBNA & neg \\
VCA-IgM & $<10$ fold \\
VCA-IgM & 10 fold \\
CMV-IgM & neg \\
CMV-IgG & neg \\
HBV-DNA & neg \\
HCV-RNA & neg \\
EBV-DNA & neg \\
HEV-RNA & 6.7 Logcopy/mL \\
HHV6-DNA & neg \\
CMV C7HRPAb & neg \\
\hline
\end{tabular}

(A) Blood examinations at the time of consultation. (B) Results of viral markers. Antibodies and RNA of hepatitis A virus (HAV), hepatitis E virus (HEV), Epstein-Barr virus (EBV), cytomegalovirus (CMV), and human herpes virus (HHV)-6 were investigated. 'neg' indicates levels that were under the sensitivity limits for the assays.

critical and chemotherapy was discontinued after the 7 th course.

The patient achieved a complete response to the treatment for Burkitt's lymphoma after the 7th chemotherapy course. No evidence of recurrence was detected by blood examinations, including tests for serum soluble IL-2 receptor and computed tomography imaging. After the final course of chemotherapy, she gradually recovered from pancytopenia and her white blood cell counts increased to a normal range. However, her serum gamma globulin concentration gradually decreased, and this was presumed to be a side effect of intensive chemotherapy. Moreover, continuous elevation of aminotransferase was observed (Fig. 1B). Serum HBs antigen and HCV antibody were not detected. Therefore, she was referred to our department.

At the first visit to our department, she reported no symptoms and no abnormality was detected by a physical examination. There was no candidate for drug-induced liver injury during chemotherapy, because liver dysfunction was persistent after the withdrawal of all drugs. The serum biochemi- cal data were as follows: AST $70 \mathrm{U} / \mathrm{L}$, ALT $111 \mathrm{U} / \mathrm{L}, \gamma$ GTP 229 U/L, and ALP 196 U/L (Table A). Tests for serological antibodies against hepatitis B virus (HBV), hepatitis $\mathrm{C}$ virus (HCV), and autoantibodies such as anti-nuclei antibody and anti-mitochondrial antibody, were negative (Table B). A diagnostic administration of ursodeoxycholic acid was not effective; therefore, a percutaneous liver biopsy was performed. A liver biopsy demonstrated that her histologic findings were consistent with chronic active hepatitis, hepatic activity index (HAI) score 7, and fibrosis stage 2 (Fig. 2). No steatosis was detected in her liver and no serological antibodies against hepatitis A virus (HAV), HEV, Epstein-Barr virus (EBV), or cytomegalovirus (CMV) were detected.

Next, we speculated that the results for serum viral antibodies may have been inaccurate due to her hypogammaglobulinemia, thus we checked for the presence of hepatitis-related viral genomes in her serum. HBV DNA, HCV RNA, EBV DNA, and human herpes virus (HHV)-6 DNA were undetectable, however, HEV RNA was detected. 

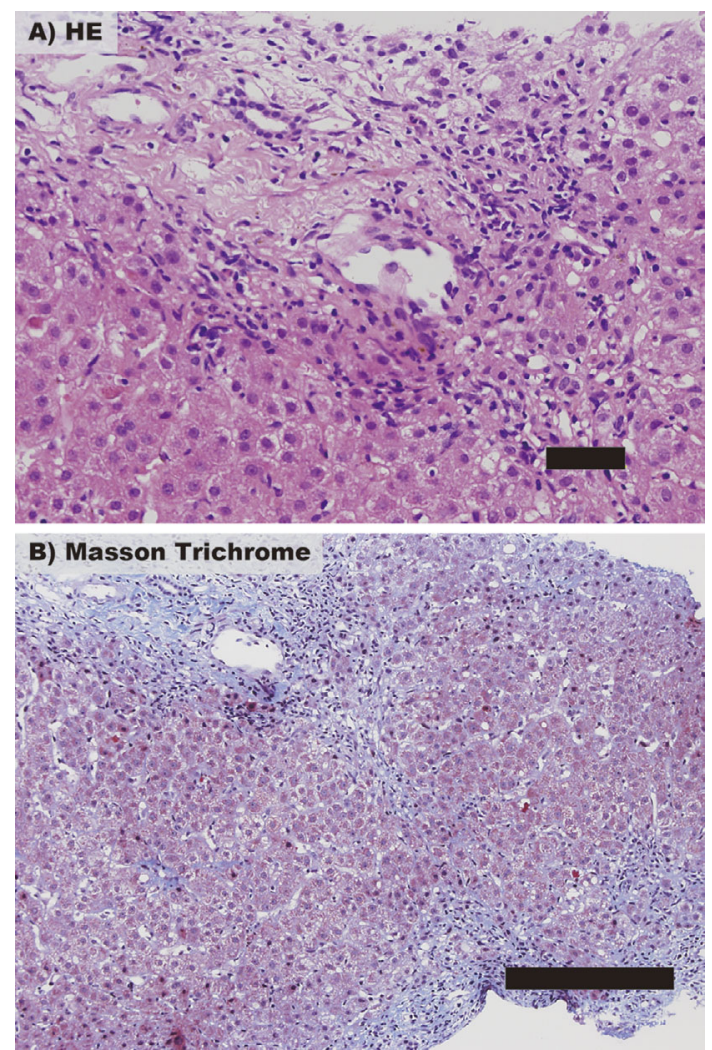

Figure 2. Histological findings of a liver biopsy. (A) Hematoxylin and Eosin staining shows mild piecemeal necrosis and moderate inflammation around the portal vein, demonstrating chronic hepatitis. Scale bar: $50 \mu \mathrm{m}$. (B) Masson's trichrome staining shows the progression of periportal fibrosis. Scale bar: $200 \mu \mathbf{m}$.

The amount of viral RNA was $6.7 \mathrm{log}$ copies/mL, and a phylogenetic tree analysis revealed that HEV in her serum was genotype 3 (Fig. 3). We could not retrospectively examine HEV RNA using her serum samples at the beginning of liver dysfunction because such samples were not preserved. She had no history of travel to HEV-endemic areas and no history of eating unsanitary or raw meat from pig, deer or any other known hosts of HEV. In order to clarify the route of infection, we retrospectively tested samples of all blood transfusions she had received during chemotherapy for the presence of HEV RNA. One sample of platelet concentrate administered during her 4th course of chemotherapy was positive for HEV RNA. Parts of open reading frame (ORF) 1 and ORF2 of the HEV-genome sequence were determined by a polymerase chain reaction (PCR)-based direct sequence method in samples from this patient and from the blood donor. The concordance rate of ORF1 and ORF2 sequences in samples obtained from both individuals were 99\% (325/326 base) and 100\% (412/412 base), respectively. We concluded that the patient had been infected with HEV by the platelet transfusion during the 4th course of chemotherapy, and $\mathrm{CH}-$ E then developed due to immunosuppression, including hypogammaglobulinemia that subsequently developed.

After the diagnosis of CH-E, the patient's hypogam- maglobulinemia was treated by $\gamma$-globulin supplementation therapy to allow her to recover from immunosuppression. However, her liver dysfunction did not improve following $\gamma$ globulin supplementation therapy and the amount of HEV RNA did not decrease. After obtaining approval for ribavirin therapy according to a previous report from the ethical committee of our hospital, the patient agreed to start ribavirin therapy. According to the previous report, ribavirin was initially administrated at a dose of approximately $8 \mathrm{mg} / \mathrm{kg} /$ day (8). Improvement in the patient's liver dysfunction was achieved after the administration of ribavirin for 5 weeks (Fig. 1B). Her serum HEV RNA levels were markedly decreased by $-3 \log$ copies/mL (Fig. 4). She developed no adverse events following ribavirin administration, however, tests for $\operatorname{IgA}$ antibody against $\mathrm{HEV}$ remained negative. Complete clearance of HEV was not achieved after the administration of ribavirin for 6 months, therefore the dose of ribavirin was increased to $10 \mathrm{mg} / \mathrm{kg} / \mathrm{day}$. Tests for serum HEV RNA remained positive even after ribavirin had been administered for 8 months.

\section{Discussion}

CH-E was first reported in a recipient of organ transplantation in 2008. Other reports also have shown the development of CH-E in immunosuppressed or immunocompromised patients, such as patients with hematologic disorders, HIV-infected patients, and patients with myelosuppression following chemotherapy. To the best of our knowledge, this case is the first confirmed case report of $\mathrm{CH}-\mathrm{E}$ and one treated with ribavirin in Japan.

Dysfunction of the immune system is closely associated with $\mathrm{CH}-\mathrm{E}$. The patient described in this case report had two essential immune disorders: bone marrow suppression due to chemotherapy against hematopoietic malignancy and prolonged hypogammaglobulinemia that had still not improved after chemotherapy ended. Following a HEVcontaminated blood transfusion, she developed severe myelosuppression over one week due to her 5th course of chemotherapy, and her white blood cell count was under $500 / \mu \mathrm{L}$. It is possible that severe immunosuppression at this point contributed to her sustained HEV viremia. Previous reports have shown that HEV infection acquired via blood transfusions can cause acute hepatitis following an incubation period from 3 weeks to 7 months after the transfusion (9). Consistent with these reports, liver dysfunction of this case was noted at 8 weeks following HEV infection, when she had recovered from immunosuppression. Her recovery from immunosuppression initiated an immune response against HEV and led to the onset of hepatitis. However, we could not retrospectively examine her serum for the presence of anti-HEV antibodies or the amount of HEV RNA at the time of chemotherapy because her previous serum samples were unfortunately not preserved.

The patient developed hypogammaglobulinemia after the end of chemotherapy. Another case of secondary hypogam- 


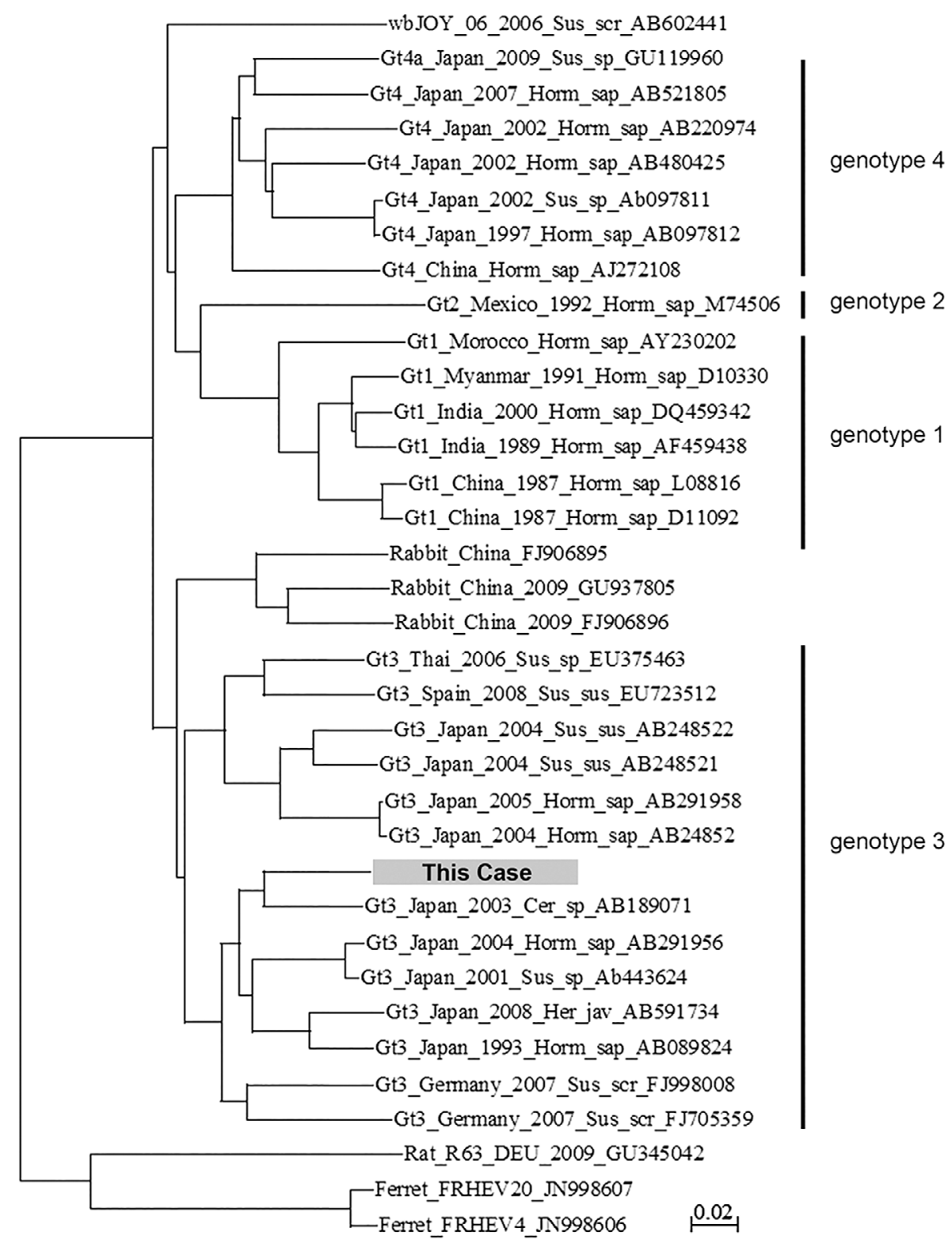

Figure 3. Phylogenetic analyses. A phylogenetic tree of HEV nucleotide sequences was constructed using the CLUSTAL W version 1.4 and MEGA version 4.0 software programs. For the phylogenetic analysis of HEV nucleotide sequences, we included sequences of several common and/or widespread strains. Each sequence name includes the genotype (Gt) and accession number. The dark box represents the sequence of the present case.

maglobulinemia after chemotherapy including rituximab has been recently reported (10). In this case, prolonged HEV infection and the onset of $\mathrm{CH}-\mathrm{E}$ were likely due to secondary hypogammaglobulinemia. A case of $\mathrm{CH}-\mathrm{E}$ with primary immunodeficiency was also reported (11). These cases indicate that HEV is not a self-limiting infection in immunosuppressed or immunocompromised patient. Thus, we strongly suggest that tests for HEV infection should be performed during the diagnostic workup of liver dysfunction in immunosuppressed or immunocompromised patients.

There is no well-established treatment for $\mathrm{CH}-\mathrm{E}$ that is supported by guidelines. If spontaneous clearance of HEV is not observed in a patient's serum, antiviral or antiinflammatory therapy should be considered to avoid the pro- gression of fibrosis. A reduction of immunosuppressive agents can eliminate $\mathrm{HEV}$ in approximately $30 \%$ of patients (12). Kamar et al. reported 59 cases of ribavirin therapy against $\mathrm{CH}-\mathrm{E}$ that developed in organ-transplant patients. The sustained virological response rate of these patients, who had undetectable serum HEV RNA at six months after treatment, was $-80 \%$ (8). Our patient did not receive any immunosuppressive medicine after the end of chemotherapy, thus ribavirin therapy was started. However, this did not eliminate HEV and we could not discontinue ribavirin therapy. As several reports have shown the efficacy of interferon therapy for $\mathrm{CH}-\mathrm{E}$, rescue treatment with interferon would be indicated to achieve HEV clearance in this case $(13,14)$. 


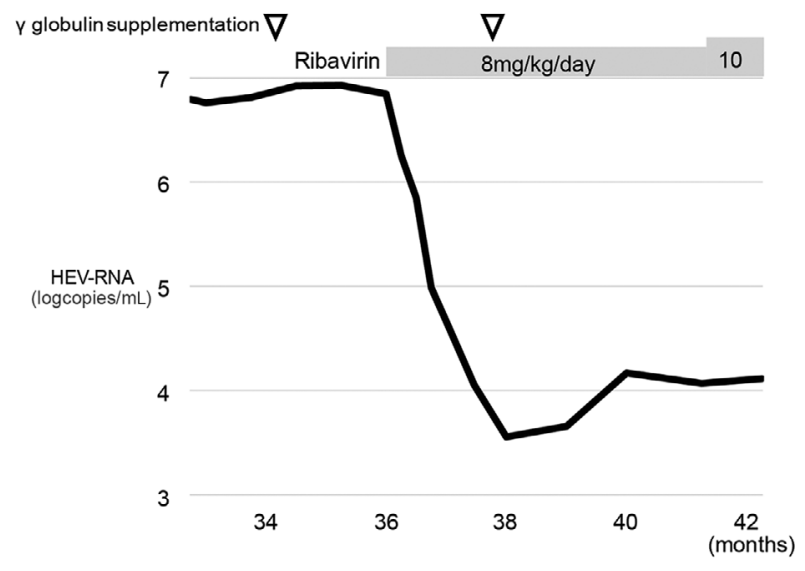

Figure 4. Changes in the serum HEV RNA levels after the diagnosis of HEV viremia. Serum HEV RNA decreased after ribavirin therapy, however, it was not eliminated after 6 months of ribavirin administration. The $x$ axis represents time from the diagnosis of lymphoma. The amounts of serum HEV RNA were quantified by quantitative RT-PCR.

The reasons why HEV is not eradicated from hosts should be investigated in view of both host and viral factors. In this case, hypogammaglobulinemia was sustained, and the patient's CD4/8 ratio was approximately 0.5 when she presented to our department, indicating that she was still immunocompromised. As HEV-specific T-cells may play a role in HEV clearance, the patient's immunocompetence is significantly important $(15,16)$. Previous reports have shown that ribavirin inhibits HEV replication, however, no direct anti-viral effect of ribavirin against HEV was noted (17). A resistant $\mathrm{HEV}$ mutation against ribavirin that increases the replication capacity of HEV has been recently reported (18). We analyzed the genomic sequence of HEV in the present case. The analysis showed that several mutations appeared after the administration of ribavirin (data not shown), however, these mutations have not been previously reported to be "resistant mutations". It is possible that ribavirin monotherapy against an immunocompromised host is insufficient to achieve HEV clearance. Further research is needed to clarify whether the identified mutations in our case are associated with HEV resistance against ribavirin.

It has been reported that only HEV genotypes 3 and 4 can cause $\mathrm{CH}-\mathrm{E}(3,19)$. Consistent with these previous reports, our case was genotype 3 , however, the mechanism by which these specific genotypes can cause $\mathrm{CH}$-E remains unknown. Although extrahepatic symptoms such as neurological injury and renal diseases have been reported in HEV patients, we observed no extrahepatic symptoms in this case (20). CH-E causes liver fibrosis and cirrhosis as well as $\mathrm{CH}$ of other etiology $(7,21)$. Therefore, it is necessary to observe the progression of liver fibrosis carefully, because the natural course and prognosis of HEV-related fibrosis remain unclear.

HEV infection due to a blood transfusion is considered to be a very rare event. In Japan, HEV screening of donated blood using HEV-nucleic acid amplification has been conducted only in Hokkaido, where the incidence rate of hepatitis $\mathrm{E}$ is relatively higher than other areas in Japan. In Hokkaido, $-0.01 \%$ of donated blood samples were positive for HEV-nucleic acid amplification (22). To the best of our knowledge, 13 patients have been infected by $\mathrm{HEV}$ via blood transfusion in Japan, including the present case (9). On the other hand, a nationwide study in England revealed that $0.04 \%$ of transfused blood contained HEV-RNA, and 18 of 43 patients who received HEV-contaminated blood developed both acute and chronic hepatitis E (23). This study showed that the positive rate for HEV-IgG and/or HEV-IgM antibodies in $\mathrm{HEV}$-infected patients via blood transfusion with immunosuppression was $70 \%$, whereas such rate without immunosuppression was $100 \%$. These data indicated that the detection of HEV antibodies in patients is influenced by immunocompetence in hosts. These data further suggested that HEV screening of donated blood is needed, at least before use in patient with immunodeficiency.

Patients with a hematologic malignancy such as lymphoma or leukemia often require intensive multi-drug chemotherapy, including molecular-targeted drugs. These patients will be immunocompromised and will need to receive frequent blood transfusions. According to the evidence presented in this case report, we recommend that testing for HEV, including HEV RNA detection, should be performed during the diagnostic workup of liver dysfunction in both immunosuppressed and immunocompromised patients. Furthermore, this case suggested that patient immunocompetence could influence the therapeutic efficacy and should be considered in determining the therapy against to $\mathrm{CH}-\mathrm{E}$.

The authors state that they have no Conflict of Interest (COI).

\section{Acknowledgement}

We thank Dr. Masahiro Satake (Japanese Red Cross Society Central Blood Center) and the staff of Japanese Red Cross Society for the retrospective survey of transfusion products, excellent technical assistance and insightful discussion.

\section{References}

1. Kamar N, Bendall R, Legrand-Abravanel F, et al. Hepatitis E. Lancet 379: 2477-2488, 2012.

2. Tei S, Kitajima N, Takahashi K, Mishiro S. Zoonotic transmission of hepatitis E virus from deer to human beings. Lancet 362: 371373, 2003.

3. Kamar N, Selves J, Mansuy JM, et al. Hepatitis E virus and chronic hepatitis in organ-transplant recipients. N Engl J Med 358: 811-817, 2008

4. Gauss A, Wenzel JJ, Flechtenmacher C, et al. Chronic hepatitis E virus infection in a patient with leukemia and elevated transaminases: a case report. J Med Case Rep 6: 334, 2012.

5. Ollier L, Tieulie N, Sanderson F, et al. Chronic hepatitis after hepatitis $\mathrm{E}$ virus infection in a patient with non-Hodgkin lymphoma taking rituximab. Ann Intern Med 150: 430-431, 2009.

6. Sellier P, Mazeron MC, Tesse S, et al. Hepatitis E virus infection in HIV-infected patients with elevated serum transaminases levels. Virol J 8: 171, 2011. 
7. Gerolami R, Moal V, Colson P. Chronic hepatitis E with cirrhosis in a kidney-transplant recipient. N Engl J Med 358: 859-860, 2008.

8. Kamar N, Izopet J, Tripon S, et al. Ribavirin for chronic hepatitis $\mathrm{E}$ virus infection in transplant recipients. $\mathrm{N}$ Engl $\mathrm{J}$ Med 370: 1111-1120, 2014.

9. Fuse K, Matsuyama $\mathrm{Y}$, Moriyama $\mathrm{M}$, et al. Late onset posttransfusion hepatitis $\mathrm{E}$ developing during chemotherapy for acute promyelocytic leukemia. Intern Med 54: 657-661, 2015.

10. Compagno N, Cinetto F, Semenzato G, Agostini C. Subcutaneous immunoglobulin in lymphoproliferative disorders and rituximabrelated secondary hypogammaglobulinemia: a single-center experience in 61 patients. Haematologica 99: 1101-1106, 2014.

11. Mallet V, Nicand E, Sultanik P, et al. Brief communication: case reports of ribavirin treatment for chronic hepatitis E. Ann Intern Med 153: 85-89, 2010.

12. Kamar N, Garrouste C, Haagsma EB, et al. Factors associated with chronic hepatitis in patients with hepatitis $\mathrm{E}$ virus infection who have received solid organ transplants. Gastroenterology 140: 1481-1489, 2011.

13. Haagsma EB, Riezebos-Brilman A, van den Berg AP, Porte RJ, Niesters HG. Treatment of chronic hepatitis $\mathrm{E}$ in liver transplant recipients with pegylated interferon alpha-2b. Liver Transpl 16: 474-477, 2010.

14. Kamar N, Rostaing L, Abravanel F, et al. Pegylated interferonalpha for treating chronic hepatitis $\mathrm{E}$ virus infection after liver transplantation. Clin Infect Dis 50: e30-e33, 2010.

15. Suneetha PV, Pischke S, Schlaphoff V, et al. Hepatitis E virus (HEV)-specific T-cell responses are associated with control of HEV infection. Hepatology 55: 695-708, 2012.
16. Kamar N, Legrand-Abravanel F, Dalton HR, Izopet J. Hepatitis E virus-specific T-cell response after transplantation. Hepatology 55: 1643; author reply 1644, 2012.

17. Kamar N, Rostaing L, Abravanel F, et al. Ribavirin therapy inhibits viral replication on patients with chronic hepatitis e virus infection. Gastroenterology 139: 1612-1618, 2010.

18. Debing Y, Gisa A, Dallmeier K, et al. A mutation in the hepatitis E virus RNA polymerase promotes its replication and associates with ribavirin treatment failure in organ transplant recipients. Gastroenterology 147: 1008-1011.e7; quiz e15-e16, 2014.

19. Wu CH, Ho CM, Tsai JH, Sun HY, Hu RH, Lee PH. First case genotype 4 hepatitis $\mathrm{E}$ infection after a liver transplant. Exp Clin Transplant (Epub ahead of print).

20. Ahmed A, Ali IA, Ghazal H, Fazili J, Nusrat S. Mystery of hepatitis e virus: recent advances in its diagnosis and management. Int J Hepatol 2015: 872431, 2015.

21. Tamura A, Shimizu YK, Tanaka T, et al. Persistent infection of hepatitis $\mathrm{E}$ virus transmitted by blood transfusion in a patient with T-cell lymphoma. Hepatology Research 37: 113-120, 2007.

22. Matubayashi K. HEV positives among blood donors in Hokkaido. Byogen Biseibutsu Kenshutsu Joho (IASR) 35: 7-8, 2014 (in Japanese).

23. Hewitt PE, Ijaz S, Brailsford SR, et al. Hepatitis E virus in blood components: a prevalence and transmission study in southeast England. Lancet 384: 1766-1773, 2014.

The Internal Medicine is an Open Access article distributed under the Creative Commons Attribution-NonCommercial-NoDerivatives 4.0 International License. To view the details of this license, please visit (https://creativecommons.org/licenses/ by-nc-nd/4.0/).

(C) 2016 The Japanese Society of Internal Medicine http://www.naika.or.jp/imonline/index.html 